\title{
SIGNIFICANCE OF 24-HOUR HOLTER MONITORING IN ACUTE ST-ELEVATION MI IN THE EARLY POST-INFARCTION PERIOD
}

\author{
Serwan Mohammed Ismail ${ }^{1}$
}

${ }^{1}$ Lecturer, Department of Internal Medicine, College of Medicine, University of Sulaimani, Kurdistan, Iraq.

ABSTRACT
BACKGROUND
Acute myocardial infarction (AMI) which is associated with complications like arrhythmias and ischemia is one of the lead cau ses
of mortality all over the world. Holter monitoring has successfully been employed to continuously monitor patients with AMI. The
present study was aimed at investigating the importance of 24-hour Holter monitoring in acute ST-elevation myocardial infarction
in the early post-infarction period.

\section{METHODS}

A total of 56 patients with acute ST-elevation myocardial infarction in Baghdad Teaching Hospital were monitored via 24-hour Holter monitoring and echocardiography as soon as they were released from coronary care unit and admitted to the medical wards. Data on age, sex, risk factors for ischemic heart disease, site of infarction, and reception of thrombolytic therapy were collected from all of the patients. The collected data was analysed using SPSS version 10.

\section{RESULTS}

Of the 56 patients with AMI, 9 were reported with significant arrhythmias, 20 with non-significant arrhythmias, and 27 without any arrhythmias. Seven patients (12.5\%) were found to have ST-depression MI for at least 1 minute during 24-hour Holter monitoring, and 5 of them (62\%) had an uneventful hospital course. The results also showed that 27 patients (48\%) had left ventricular dysfunction, and 23 of them had abnormal Holter findings (arrhythmias and/or ST depression). Moreover, 11 of the 13 patients with LV dysfunction had cardiac events.

\section{CONCLUSIONS}

Ventricular arrhythmia and LV dysfunction were found to be indicators of cardiac events in patients with AMI, which can be monitored through 24-hour Holter monitoring. Therefore, utilisation of this monitoring technique is recommended for all patients with AMI once they are admitted in medical wards.

\section{KEY WORDS}

Acute Myocardial Infarction, 24-Hour Holter Monitoring, Arrhythmia, Left Ventricular Dysfunction

HOW TO CITE THIS ARTICLE: Ismail SM. Significance of 24-hour Holter monitoring in acute ST- elevation mi in the early postinfarction period. J. Evolution Med. Dent. Sci. 2019;8(23):1862-1866, DOI: 10.14260/jemds/2019/409

\section{BACKGROUND}

In spite of numerous medical advances, acute myocardial infarction (AMI) still causes death in one third of patients.[1] Research has also revealed that the incidence of AMI is decreasing throughout the world, particularly in those countries with high per capita incomes. ${ }^{[2,3]}$ Research carried out in Iraq has reported that the incidence rate of AMI in this country is $36.2 \% .^{[4]}$

Myocardial ischemia, extent of coronary artery disease, occurrence of ventricular arrhythmias, and left ventricular function have been referred as the most significant complications caused by AMI.[5,6] Among the abovementioned complications and after intensive cardiac care units were established in hospitals, arrhythmias which usually occur during or after an acute coronary syndrome (ACS) have been reported as the most frequently modifiable and controllable ones.[7]

'Financial or Other Competing Interest': None.

Submission 25-03-2019, Peer Review 26-05-2019,

Acceptance 01-06-2019, Published 10-06-2019.

Corresponding Author:

Serwan Mohammed Ismail,

Lecturer, Department of Internal Medicine,

College of Medicine, University of Sulaimani,

Kurdistan, Iraq.

E-mail: serwan.ismail@univsul.edu.iq

DOI: 10.14260/jemds/2019/409

\section{(c) $($ ()) $\odot$}

If the patient is provided with continuous cardiac monitoring following MI.[8] Research has indicated that cardiac rhythm abnormality occurs in $90 \%$ of patients with AMI.[9]

Another important complication induced by AMI is ischemia which can result in cell death and irreversible myocardial damages in prolonged cases of ischemia.[10] Research has demonstrated that if ischemia is reversed quickly, myocardial tissue can be protected from damage.[11] For this purpose, timely diagnosis of ischemic events seems quite crucial.

Over the past decades, numerous methods have been introduced to diagnose acute myocardial infarction (AMI), among which Holter monitoring (Also called continuous ambulatory electrocardiography) has been proved to be one of the most cost-effective clinical tools for diagnosis and assessment of AMI and its induced complications such as cardiac arrhythmias (Symptomatic or asymptomatic) and silent ischemia.[12-14] Holter monitoring is conventionally conducted in either 24- or 48-hour post-infarction periods. This method has been employed to diagnose arrhythmias, assess risk and prognosis, evaluate the therapeutic interventions, and evaluate the pacemakers.[15] Echocardiography has also been proposed as an essential non-invasive diagnostic technique for diagnosing acute coronary.[16] 


\begin{tabular}{|c|c|c|c|c|}
\hline \multicolumn{2}{|c|}{ Variable } & N & $\%$ & p-Value \\
\hline \multirow{2}{*}{$\begin{array}{c}\text { No significant } \\
\text { arrhythmias }\end{array}$} & $\begin{array}{c}\text { Eventful hospital } \\
\text { course '6' }\end{array}$ & $6 / 47$ & 10 & \\
\cline { 2 - 4 } & $\begin{array}{c}\text { '4table hospital course } \\
\text { '41' }\end{array}$ & $41 / 47$ & 90 & \multirow{2}{*}{0.0002} \\
\hline \multirow{2}{*}{$\begin{array}{c}\text { Significant } \\
\text { arrhythmias }\end{array}$} & $\begin{array}{c}\text { Eventful hospital } \\
\text { course '7' }\end{array}$ & $7 / 9$ & 77.8 & \\
\cline { 2 - 4 } & $\begin{array}{c}\text { Stable hospital course } \\
\text { '2' }\end{array}$ & $2 / 9$ & 22.2 & \\
\hline \multicolumn{3}{|c|}{$\begin{array}{r}\text { Table 1. Relationship Between Significant Arrhythmias on } \\
\text { Holter Monitoring to Eventful Hospital Course }\end{array}$} \\
\hline
\end{tabular}

\begin{tabular}{|c|c|c|c|c|}
\hline \multicolumn{2}{|c|}{ Variable } & $\mathbf{N}$ & $\%$ & p-Value \\
\hline \multirow{2}{*}{$\begin{array}{c}\text { No ST } \\
\text { depression on } \\
\text { Holter }\end{array}$} & $\begin{array}{c}\text { Eventful hospital } \\
\text { course '8' } \\
\end{array}$ & $8 / 49$ & 16.3 & \multirow{4}{*}{0.005} \\
\hline & $\begin{array}{c}\text { Stable hospital } \\
\text { course ' } 41 \text { ' }\end{array}$ & $41 / 49$ & 83.7 & \\
\hline \multirow{2}{*}{$\begin{array}{c}\text { ST depression on } \\
\text { Holter }\end{array}$} & $\begin{array}{l}\text { Eventful hospital } \\
\text { course ' } 5 \text { ' }\end{array}$ & $5 / 7$ & 61.5 & \\
\hline & $\begin{array}{l}\text { Stable hospital } \\
\text { course '2' }\end{array}$ & $2 / 7$ & 38.5 & \\
\hline
\end{tabular}

Table 2. Relationship Between ST Segment Depression on Holter Monitoring and Hospital Course in Acute ST Elevation MI

\begin{tabular}{|c|c|c|c|c|}
\hline \multicolumn{2}{|c|}{ Variable } & N & $\%$ & p-Value \\
\hline \multirow{2}{*}{$\begin{array}{c}\text { LV } \\
\text { dysfunction }\end{array}$} & $\begin{array}{c}\text { Abnormal findings on } \\
\text { Holter }\end{array}$ & 23.27 & 84.7 & \\
\cline { 2 - 4 } & Normal Holter finding & 4.27 & 15.3 & \multirow{2}{*}{0.0004} \\
\hline \multirow{2}{*}{$\begin{array}{c}\text { Normal LV } \\
\text { dysfunction }\end{array}$} & $\begin{array}{c}\text { Abnormal findings on } \\
\text { Holter }\end{array}$ & $7 / 30$ & 23.3 & \\
\cline { 2 - 4 } & Normal Holter finding & $23 / 30$ & 76.7 & \\
\cline { 1 - 3 } $\begin{array}{c}\text { Table 3. Relationship Between Arrhythmias and/or ST Segment } \\
\text { Depression on Holter Monitoring and LV Dysfunction (By } \\
\text { Echocardiography) }\end{array}$ \\
\hline
\end{tabular}

\begin{tabular}{|c|c|c|c|c|}
\hline \multicolumn{2}{|c|}{ Variable } & N & \% & p-Value \\
\hline \multirow{2}{*}{ Cardiac events* * Reduced EF "11" } & $11 / 13$ & 85 & \\
\cline { 2 - 4 } & Normal EF "2" & $2 / 13$ & 15 & \multirow{2}{*}{0.007} \\
\cline { 2 - 4 } $\begin{array}{c}\text { No cardiac } \\
\text { events }\end{array}$ & Reduced EF “16" & $16 / 43$ & 35 & \\
\cline { 2 - 4 } & Normal EF "27" & $27 / 43$ & 65 & \\
\hline \multicolumn{3}{|c|}{ Table 4. Relationship Between Cardiac Events in } \\
Hospital and LV Function by (EF) \\
\hline *Cardiac events include significant arrhythmias, post-infarction angina, \\
reinfarction, heart failure, stroke, or death. \\
\hline
\end{tabular}

\begin{tabular}{|c|c|c|c|c|}
\hline \multicolumn{2}{|c|}{ Variable } & $\mathbf{N}$ & $\%$ & p-Value \\
\hline \multirow{2}{*}{$\begin{array}{c}\text { Anterior Wall } \\
\text { MI }\end{array}$} & $\begin{array}{l}\text { Abnormal Holter } \\
\text { findings ' } 9 \text { ' }\end{array}$ & $9 / 19$ & 47.3 & \multirow{14}{*}{0.18} \\
\hline & Normal Holter ' 10 ' & $10 / 19$ & 52.7 & \\
\hline \multirow{2}{*}{$\begin{array}{l}\text { Inferior Wall } \\
\text { MI }\end{array}$} & $\begin{array}{l}\text { Abnormal Holter } \\
\text { findings ' } 11 \text { ' }\end{array}$ & $11 / 19$ & 57.9 & \\
\hline & Normal Holter '8' & $8 / 19$ & 42.1 & \\
\hline \multirow{2}{*}{$\begin{array}{l}\text { Lateral Wall } \\
\quad \text { MI }\end{array}$} & $\begin{array}{l}\text { Abnormal Holter } \\
\text { findings '2' }\end{array}$ & $2 / 8$ & 25 & \\
\hline & Normal Holter '6' & $6 / 8$ & 75 & \\
\hline \multirow{2}{*}{$\begin{array}{l}\text { Anterolat. } \\
\text { Wall MI }\end{array}$} & $\begin{array}{l}\text { Abnormal Holter } \\
\text { findings ' } 6 \text { ' }\end{array}$ & $6 / 7$ & 85.7 & \\
\hline & Normal Holter '1' & $1 / 7$ & 14.3 & \\
\hline \multirow{2}{*}{$\begin{array}{l}\text { Inferolat. Wall } \\
\text { MI }\end{array}$} & $\begin{array}{l}\text { Abnormal Holter } \\
\text { findings ' } 1 \text { ' }\end{array}$ & $1 / 1$ & 100 & \\
\hline & Normal Holter '0' & $0 / 1$ & 0 & \\
\hline \multirow{2}{*}{$\begin{array}{c}\mathrm{INF}+\mathrm{RV} \text { Wall } \\
\mathrm{MI}\end{array}$} & $\begin{array}{l}\text { Abnormal Holter } \\
\text { findings ' } 1 \text { ' }\end{array}$ & $1 / 1$ & 100 & \\
\hline & Normal Holter '0' & $0 / 1$ & 0 & \\
\hline \multirow{2}{*}{$\begin{array}{l}\text { Anterosep. } \\
\text { Wall MI }\end{array}$} & $\begin{array}{l}\text { Abnormal Holter } \\
\text { findings ' } 1 \text { ' }\end{array}$ & $1 / 1$ & 100 & \\
\hline & Normal Holter '0' & $0 / 1$ & 0 & \\
\hline \multicolumn{5}{|c|}{$\begin{array}{l}\text { Table 5. Relationship Between Wall of Heart Infracted and } \\
\text { Arrhythmias and/or ST Depression }\end{array}$} \\
\hline
\end{tabular}

The present study was carried out in order to examine the significance of 24-hour Holter monitoring (For arrhythmias and ischemia) and echocardiography during the early postinfarction period in patients with acute ST elevation myocardial infarction before discharge from hospital.

\section{METHODS}

The present investigation was a cross-sectional study was conducted over a period of 8 months from May 1 to December 31, 2006. Since the study was carried out in only one coronary care unit in Baghdad and only 56 patients (42 males and 14 females) with acute ST-elevation myocardial infarction and the study's inclusion criteria discharged from coronary care unit to the medical wards in Baghdad Teaching Hospital during the study period, those 56 patients were recruited as the study sample. All of the patients were provided with 24-hour Holter monitoring and echocardiography. The Holter monitoring also included ST segment monitoring.

The target patients were selected some inclusion criteria. All of the patients had acute ST-elevation myocardial infarction. The diagnosis was based on sequential ECG including ST segment elevation $1 \mathrm{~mm}$ or more in at least 2 successive contiguous leads, $\mathrm{T}$ wave changes $\pm \mathrm{Q}$ wave with either a history of ischemic-type discomfort or pain or rise in cardiac enzyme activity to at least twice the upper limit of normal for the hospital laboratory.

Required data including age, sex, risk factors for ischemic heart disease (Hypertension, diabetes mellitus, smoking, etc.), site of infarction (Anterior, interior, or lateral wall, etc.), and reception of thrombolytic therapy or not were collected from all of the patients. Special attention was paid to the patients hospitalization course which was considered as eventful if the patient developed significant arrhythmias, post-infarction angina, reinfarction, heart failure, stroke, or death.

All patients were monitored by 24-hour Holter monitoring immediately after discharge from CCU to the medical wards. The obtained tapes were analysed for-

1. Significant arrhythmia including frequent premature ventricular contractions (PVC) $>5 /$ hour, ventricular tachycardia (VT) $>3$ beats successively at a heart rate above 100/minute (Regarded as non-sustained VT if terminated in less than 30 seconds and as sustained VT if it continued for more than 30 seconds), ventricular fibrillation, persistent atrial fibrillation (AF) or supraventricular tachycardia, and second-degree or complete heart block.

2. ST segment monitoring for ischemia. Ischemic episodes defined as ST depression $\geq 1 \mathrm{~mm}$ for $\geq 1$ minute $80 \mathrm{~ms}$ after the J point. During Holter monitoring, positive symptoms were interpreted as presence of palpitation, syncope, chest pain, or discomfort and negative symptoms were considered as their absence. Moreover, the patients underwent trans-thoracic echocardiography for possible left ventricular (LV) dysfunction which was considered present if ejection fraction (EF) was lower than $50 \%$.

\section{Statistical Analysis}

Data analysis was carried out through Statistical Package for Social Science (SPSS v. 10). Chi-square test was utilized to measure associations between the study's different variables. Also, Chi-square test was used to check differences between the variables. The results were expressed using numbers and percentages. In all statistical tests, $\mathrm{p}<0.05$ was considered as level of significance. 


\section{RESULTS}

The results of the present study obtained from 24-hour Holter monitoring revealed that of the 56 patients with ST elevation MI, 29 (52\%) had arrhythmias. Of those 29 patients, 9 cases were significant arrhythmias with PVC $>5$ /hour in 5 patients (9\%), PVC $>5 /$ hour with non-sustained VT in 3 patients (5\%), and PVC $>5 /$ hour with supra-ventricular tachycardia in 1 patient $(<2 \%)$. The rest 20 cases were nonsignificant arrhythmias with PVC $<5 / \mathrm{hr}$ in 7 patients $(12 \%)$, sinus tachycardia in2 patients (3\%), supra-ventricular ectopics in 4 patients (7\%), sinus bradycardia in 2 patients $(3 \%)$, sinus pauses alone in 1 patient $(<2 \%)$, paroxysmal $\mathrm{AF}$ in 3 patients $(5 \%)$, and short sinus pauses $+2^{\text {nd }}$ degree $A v$ block (Wenckebach) in 1 patient $(<2 \%)$. It was revealed that 27 patients did not have arrhythmia.

Data analysis also showed that 9 patients (78\%) with significant arrhythmias had an eventful hospital course. Of the patients with no arrhythmias and those with nonsignificant arrhythmias $(n=47)$, only $6(10 \%)$ had an eventful hospital course $(p=0.0002)$ (See Table 1). Moreover, sustained VT and VF were not found, and death rate, stroke, and re-infarction were zero.

Data analysis also indicated that 7 patients $(12.5 \%)$ had ST depression of myocardial ischemia for at least 1 minute during 24-hour Holter monitoring. Of those patients, 5 (62\%) had an eventful hospital course compared to the 8 patients (16\%) of the 49 patients without ST depression, and in this regard, the two groups were significantly different at $\mathrm{p}=0.005$ (See Table 2).

According to the obtained results, a total of 27 patients (48\%) had LV dysfunction (ejection fraction $<50 \%$ ). It was also observed that 23 patients $(84.7 \%)$ of those patients with LV dysfunction had abnormal findings (arrhythmias and/or ST depression) on 24-hour Holter monitoring compared to those 7 patients $(23.3 \%)$ with normal LV function, and in this regard, the two groups were significantly different at $\mathrm{p}=0.0004$ (See Table 3).

The results of data analysis also demonstrated that 11 patients $(85 \%)$ out of 13 with LV dysfunction had cardiac events compared to the 16 patients (35) with LV dysfunction without cardiac events, and in this regard, the two groups were significantly different at $\mathrm{p}=0.007$ (See Table 4).

The results also revealed that there was no significant relationship between the site of heart wall infracted and arrhythmias and/or ST depression on 24-hour Holter monitoring ( $\mathrm{p}=0.18$ ) (See table 5).

Moreover, the results of data analysis showed that there was no significant relationship between serum potassium levels (s.k+) and significant arrhythmias on 24-hour Holter monitoring in the early post-infarction period $(\mathrm{p}=0.102)$. It was also observed that there was no significant relationship between patients received thrombolytic therapy or not and significant arrhythmias on 24-hour Holter monitoring $(\mathrm{p}=0.537)$.

\section{DISCUSSION}

Numerous studies have put emphasis on the significance of cardiac arrhythmias in patients with acute ST-elevation myocardial infarction.[17-19] Such patients are usually monitored closely while they are in coronary care unit. In the present study, the state of arrhythmias after discharge from coronary unit among patients with acute myocardial infarction was examined.

Premature ventricular contraction (PVC), non-sustained VT (NSVT), and sustained VT or ventricular fibrillation are the arrhythmias that have been reported to be correlated with sudden cardiac death (SCD) risk. ${ }^{[20,21]}$ The results of the present study revealed that the incidence of $\mathrm{PVC}>5 / \mathrm{hr}$ was $16 \%$, while non-sustained VT was $5 \%$. In their study of Holter recording in patients before hospital discharge, Huikuri et al. (2003) reported that $14 \%$ of the patients had non-sustained VT, and mortality rate increased among them after 1 year.[20]

Results obtained from 24- to 48-hour Holter monitoring have indicated that the estimate prevalence of PVCs in the general population was between $40 \%$ and $75 \% .{ }^{[22]}$ Prevalence of PVCs was reported to be $27.6 \%$ in a study carried out by Temiz et al. (2014).[23] The frequency of PVCs in the present study was less than the abovementioned studies, which may be related to the fact that, unlike those studies, the patients in the present study were monitored in the post-acute phase of infarction. In their study, Martin et al. (2003) reported that the prevalence of NSVT was $20 \%$ and PVC 29\% which increased after 1 year. They also found that NSVT and PVC were significantly related to LV size and function. ${ }^{[21]}$

In the present study, patients with ventricular arrhythmias who were found to have a high risk for hospital cardiac event (ranging from post-MI angina to severe cardiac failure) were those with frequent premature ventricular contraction and/or ventricular tachycardia, with an event rate of $77 \%$ compared to $10 \%$ in those without such arrhythmias, and this difference was significant at $\mathrm{p}=0.0002$. Similar results have been reported by Dahlin et al. (2014) and Proietti et al. (2016).[24,25]

Atrial fibrillation (AF) has been referred to as the most common supra-ventricular arrhythmia after an MI. The association of AF with increased mortality, which has been reported in a study conducted by Miyasaka et al. (2007),[26] is not due to arrhythmia itself, but to factors associated with it especially heart failure, shock, or serious ventricular arrhythmia. ${ }^{27,28]}$ In the present study, AF was found in 5\% of the patients. Research has indicated that $\mathrm{AF}$ is more common in patients with hemodynamic or arrhythmic complications.[27] The results of the present study are in line with other studies with slight differences which can be attributed to different time of monitoring in different studies.

Silent ischemia has been reported to be associated with 5fold rise in risk of cardiac events. [29] In the present study, $12.5 \%$ of the patients had ischemic ST segment depression. It was also seen that $61.5 \%$ of the patients with ischemic ST segment depression had cardiac events, while only $16.3 \%$ of those without ischemic experienced cardiac events, and this difference was significant at $\mathrm{p}=0.005$. Similar results have been reported in previously conducted studies.[30,31]

The results of the present study indicated that $48 \%$ of the patients had LV dysfunction which was found to be strongly associated with occurrence of cardiac events, such that $76.6^{\wedge}$ of the patients with LV dysfunction had cardiac events, while only $15.3 \%$ without LV dysfunction underwent cardiac events, and this difference was significant at $p=0.0004$. This finding is in line with that of the study carried out by Blecker et al. (2010) who introduced left ventricular dysfunction as a major risk factor for cardiovascular hospitalization. [32] 
The results of the current investigation revealed that $85 \%$ of the patients who had ejection fraction (EF) underwent cardiac events, while $35 \%$ without it had cardiac events, and this difference was significant at $p=0.007$. This finding is similar to those of other previously conducted studies.[33-35]

In the present study, no significant relationship was found between abnormal Holter finding and thrombolytic therapy administration, which is in line with the study carried out by Otasevic et al. (2003) who reported stated that thrombolysis per se had no influence on the incidence of complex ventricular arrhythmias in the late hospital phase after the first acute myocardial infarction. ${ }^{[36]}$

\section{CONCLUSIONS}

Ventricular arrhythmia is an indicator of cardiac events in patients with acute ST-elevation MI in the early postinfarction period. In those patients; moreover, LV dysfunction was an indicator of cardiac events. In addition, there was a significant relationship between LV dysfunction and abnormal Holter findings. Also, incidence of arrhythmias and ischemic ST depression was seen in patients with LV dysfunction. Therefore, 24-hour Holter monitoring is recommended to be carried out for all patients with STelevation MI on their admission to medical wards.

\section{REFERENCES}

[1] Aso $\mathrm{S}$, Imamura $\mathrm{H}$, Sekiguchi $\mathrm{Y}$, et al. Incidence and mortality of acute myocardial infarction. A populationbased study including patients with out-of-hospital cardiac arrest. Int Heart J 2011;52(4):197-202.

[2] Nichols M, Townsend N, Scarborough P, et al. Cardiovascular disease in Europe 2014: epidemiological update. Eur Heart J 2014;35(42):2929-33.

[3] Mozaffarian D, Benjamin EJ, Go AS, et al. Heart disease and stroke statistics - 2015 update: a report from the American Heart Association. Circulation 2015;131(4):e29-e322.

[4] Hamid MB. Clinical characteristics and outcomes of acute coronary syndromes in a group of Iraqi patients. Iraqi JMS 2016;14(4):304-11.

[5] Taylor G, Humphries JO, Mellits ED, et al. Predictors of clinical course coronary anatomy and left ventricular function after recovery from acute myocardial infarction. Circulation 1980;62(5):960-70.

[6] Bigger JT Jr, Fleiss JL, Kleiger R, et al. The relationships among ventricular arrhythmias, left ventricular dysfunction and mortality in the 2 years after myocardial infarction. Circulation 1984;69(2):250-8.

[7] Mhatre MA, Sirur FM, Rajpal DR, et al. A clinical study of arrhythmias associated with acute myocardial infarction and thrombolysis. International Journal of Research in Medical Sciences 2016;5:335. DOI: 10.18203/2320-6012.ijrms20164574.

[8] Rajhans R, Narayanan M. Assessment of arrhythmias in 50 patients of ST-elevation myocardial infarction after thrombolysis: a 24 hour Holter study. International Journal of Advances in Medicine 2017;4(3):734-40.
[9] Perron AD, Sweeney T. Arrhythmic complications of acute coronary syndromes. Emerg Med Clin North Am 2005;23(4):1065-82.

[10] Kalogeris T, Baines CP, Krenz M, et al. Ischemia/Reperfusion. Compr Physiol 2016;7(1):11370.

[11] Hausenloy DJ, Yellon DM. Myocardial ischemiareperfusion injury: a neglected therapeutic target. J Clin Invest 2013;123(1):92-100.

[12] Galli A, Ambrosini F, Lombardi F. Holter monitoring and loop recorders: from research to clinical practice. Arrhythm Electrophysiol Rev 2016;5(2):136-43.

[13] Hegazy RA, Lotfy WN. The value of Holter monitoring in the assessment of Pediatric patients. Indian Pacing Electrophysiol J 2007;7(4):204-14.

[14] Nakao YM, Ueshima $K$, Nohara $R$, et al. Holter monitoring for the screening of cardiac disease in diabetes mellitus: The non-invasive Holter monitoring observation of new cardiac events in diabetics study. Diabetes \& Vascular Disease Research 2015;12(6):396-404.

[15] Zimetbaum PJ, Josephson ME. The evolving role of ambulatory arrhythmia monitoring in general clinical practice. Ann Intern Med 1999;130(10):848-56.

[16] Esmaeilzadeh M, Parsaee M, Maleki M. The role of echocardiography in coronary artery disease and acute myocardial infarction. J Tehran Heart Cent 2013;8(1):1-13.

[17] Winkler C, Funk M, Schindler DM, et al. Arrhythmias in patients with acute coronary syndrome in the first 24 hours of hospitalization. Heart Lung 2013;42(6):4227.

[18] Gorenek B, Lundqvist BC, Terradellas BJ, et al. Cardiac arrhythmias in acute coronary syndromes: position paper from the joint EHRA, ACCA and EAPCI task force. Europace 2014;16(11):1655-73.

[19] Marangmei L, Singh SK, Devi KB, et al. Profile of cardiac arrhythmia in acute myocardial infarction patients within 48 hours of admission: a hospital based study at RIMS Imphal. J Med Soc 2014;28(3):175-9.

[20] Huikuri HV, Mahaux V, Bloch-Thomsen PE. Cardiac arrhythmias and risk stratification after myocardial infarction: results of the CARISMA pilot study. Pacing Clin Electrophysiol 2003;26(1 Pt 2):416-9.

[21] St. John SM, Lee D, Rouleau JL, et al. Left ventricular remodeling and ventricular arrhythmias after myocardial infarction. Circulation 2003;107(20):2577-82.

[22] Ng GA. Treating patients with ventricular ectopic beats. Heart 2006;92(11):1707-12.

[23] Temiz A, Gazi E, Altun B, et al. Fragmented QRS is associated with frequency of premature ventricular contractions in patients without overt cardiac disease. Anatol J Cardiol 2015;15(6):456-62.

[24] Dahlin AA, Parsons CC, Barengo NC, et al. Association of ventricular arrhythmia and in-hospital mortality in stroke patients in Florida: a non-concurrent prospective study. Medicine (Baltimore) 2017;96(28):e7403. 
[25] Proietti R, Joza J, Essebag V. Therapy for ventricular arrhythmias in structural heart disease: a multifaceted challenge. J Physiol 2016;594(9):2431-43.

[26] Miyasaka Y, Barnes ME, Bailey KR, et al. Mortality trends in patients diagnosed with first atrial fibrillation: a 21-year community-based study. J Am Coll Cardiol 2007;49(9):986-92.

[27] Pizzetti F, Turazza FM, Franzosi MG, et al. Incidence and prognostic significance of atrial fibrillation in acute myocardial infarction: the GISSI-3 data. Heart 2001;86(5):527-32.

[28] Marchioli R, Avanzini F, Barzi F, et al. Assessment of absolute risk of death after myocardial infarction by use of multiple-risk-factor assessment equations: GISSI-Prevenzione mortality risk chart. Eur Heart J 2001;22(22):2085-103.

[29] Cohn PF, Fox KM, Daly C. Silent myocardial ischemia. Circulation 2003;108(10):1263-77.

[30] Lanza GA, Mustilli M, Sestito A, et al. Diagnostic and prognostic value of ST segment depression limited to the recovery phase of exercise stress test. Heart 2004;90(12):1417-21.

[31] Uen S, Fimmers R, Weisser B, et al. ST segment depression in hypertensive patients: a comparison of exercise test versus Holter ECG. Vasc Health Risk Manag 2008;4(5):1073-80.
[32] Blecker S, Matsushita K, Fox E, et al. Left ventricular dysfunction as a risk factor for cardiovascular and non-cardiovascular hospitalizations in African Americans. Am Heart J 2010;160(3):488-95.

[33] Goto T, Wakami K, Fukuta H, et al. Patients with left ventricular ejection fraction greater than $58 \%$ have fewer incidences of future acute decompensated heart failure admission and all-cause mortality. Heart Vessels 2016;31(5):734-43.

[34] Di Tullio MR, Qian M, Thompson JL, et al. Left ventricular ejection fraction and risk of stroke and cardiac events in heart failure: data from the warfarin versus aspirin in reduced ejection fraction trial. Stroke 2016;47(8):2031-7.

[35] Buxton AE, Lee KL, Hafley GE, et al. Relation of ejection fraction and inducible ventricular tachycardia to mode of death in patients with coronary artery disease: an analysis of patients enrolled in the multicenter unsustained tachycardia trial. Circulation 2002;106(19):2466-72.

[36] Otasevic P, Neskovic AN, Popovic Z, et al. Effect of thrombolytic therapy on occurrence of complex ventricular arrhythmias in the late hospitalization period in acute myocardial infarct: relation with longterm remodeling of the left ventricle. Vojnosanit Pregl 2003;60(5):547-53. 